\section{Alkaline Peroxides Versus Sodium Hypochlorite for Removing Denture Biofilm: a Crossover Randomized Trial}

\author{
Amanda Peracini ${ }^{1}$, Rômulo Rocha Regis ${ }^{2}$, Raphael Freitas de Souza ${ }^{1}$, Valéria \\ Oliveira Pagnano ${ }^{1}$, Cláudia Helena Lovato da Silva ${ }^{1}$, Helena de Freitas \\ Oliveira Paranhos ${ }^{1}$
}

'Department of Dental Materials and Prosthetics, School of Dentistry of Ribeirão Preto, USP - University of São Paulo, Ribeirão Preto, SP, Brazil. ${ }^{2}$ School of Dentistry, Federal University of Ceará, Fortaleza, CE, Brazil.

Correspondence: Helena de Freitas Oliveira Paranhos. Avenida do Café S/N, 14040-904, Ribeirão Preto,SP, Brasil. Tel: +55-16-3315-4031. e-mail: helenpar@forp.usp.br

\begin{abstract}
This study evaluated the efficacy of cleanser solutions on denture biofilm removal by a crossover randomized clinical trial. Thirty two edentulous patients were instructed to brush their dentures (specific brush and liquid soap) three times a day (after breakfast, lunch and dinner) and to soak them ( $\geq 8 \mathrm{~h}$ ) in: (C) control-water; (AP): alkaline peroxide; or (SH) $0.5 \%$ sodium hypochlorite. Each solution was used for 21 days (three cycles of 7 days). At the end of each cycle, the inner surfaces of maxillary dentures were disclosed (1\% neutral red) and photographed ( $\mathrm{HX} 1$ - Sony). Areas (total and stained biofilm) were measured (Image Tool software) and the percentage of biofilm calculated as the ratio between the area of the biofilm multiplied by 100 and total surface area of the internal base of the denture. Data were compared by means of generalized estimating equation $(\alpha=5 \%)$ and multiple comparisons (Bonferroni; $\alpha=1.67 \%$ ). Immersion in SH reduced biofilm $(\%)\left(8.3 \pm 13.3^{\mathrm{B}}\right)$ compared to $\mathrm{C}\left(18.2 \pm 14.9^{\mathrm{A}}\right)$ and $\mathrm{AP}\left(18.2 \pm 16.6^{\mathrm{A}}\right)$. The $0.5 \%$ sodium hypochlorite solution was the most efficacious for biofilm removal. Alkaline peroxides may not lead to further biofilm removal in patients with adequate denture maintenance habits.
\end{abstract}

Key Words: biofilm, denture cleansers, randomized controlled trial

\section{Introduction}

Complete denture hygiene is crucial for the maintenance of oral health for edentulous patients. Despite the variety of existing methods, there is no consensus regarding the most effective form for denture cleansing $(1,2)$. Cleaning methods can be classified as chemical or mechanical according to their main mechanism of action, with the possibility of combined use. In general, the mode of use for chemical methods involves soaking dentures in a solution for either short (3 to $20 \mathrm{~min})$ or long $(8 \mathrm{~h})$ periods. The alkaline peroxides and sodium hypochlorite are the most used agents and their clinical effectiveness has been tested by microbiological and stained biofilm quantifications (3-13).

The alkaline peroxide solutions are widely indicated for controlling of biofilm, however the efficacious of such agents is still inconclusive. Some studies show ineffectiveness on biofilm removal (14-17) while others demonstrate that these solutions can incorporate a cleaning action in the hygiene procedure $(4,5,18)$ and may be useful as an adjunct method of brushing $(6-8,10,12)$. Hypochlorite solutions have been indicated as effective chemical method of hygienic $(11,12,17,19,20)$; however, the concentration is a factor that should be considered to prevent any adverse effects on the materials of the prosthetic devices $(21,22)$. The majority of these works evaluated the effectiveness of these solutions in short periods of immersion; moreover, few clinical studies have been carried out in compliance with approaches for minimizing biases (2). Therefore, denture cleansers are still a reasonable subject for randomized controlled trials.

A preventive and curative practice refers to the recommended overnight removal of the prosthesis and immersion in cleansing solutions. Thus, it is important to evaluate the ability to remove biofilm of chemical hygienic solutions when used overnight. Therefore, the purpose of this study was to analyze the efficacy of two denture cleansers (effervescent tablet and 0.5\% sodium hypochlorite) in terms of biofilm removal through a cross-over randomized clinical trial on complete denture wearers. The null hypothesis was that overnight immersion in denture cleansers and a control medium would have the same ability to remove biofilm.

\section{Material and Methods}

Forty-two adult patients (20 men and 30 women) with a mean age of $60.5 \pm 9.0$ years (range: $50-80$ years) were selected for the trial after approval by the Institutional Review Board (CAAE 0036.0.138.000-10). Participants were enrolled among regular patients of the School of Dentistry of Ribeirao Preto's complete denture clinic within a 21-month period. Inclusion criteria were: complete edentulism, use of heat-polymerized acrylic resin maxillary 
dentures, good overall health, no clinical diagnosis of denture stomatitis and presence of biofilm on the internal surface of dentures according to the Additive Index (6). There was no restriction on gender. Participants were excluded if existing dentures that had less than one year of use or were broken, fractured or relined.

Common procedures for all participants involved instructions for brushing dentures after main meals (breakfast, lunch and dinner) by using a denture-specific brush (Condor SA, Sao Bento do Sul, SC, Brazil) with neutral liquid soap (Pleasant, Perol, Ribeirao Preto, SP, Brazil). Trial interventions comprised overnight immersion of dentures (minimum of $8 \mathrm{~h}$ ) in $(200 \mathrm{~mL})$ : (C): Control - water at room temperature $\left(23 \pm 2{ }^{\circ} \mathrm{C}\right)$; (AP): Alkaline peroxide solution one effervescent tablet in warm water $\left(37 \pm 2{ }^{\circ} \mathrm{C}\right.$ ) (Corega Tabs, GlaxoSmithKline Brazil, Sao Paulo, SP, Brazil); (SH): 0.5\% Sodium Hypochlorite solution (manipulated solution, Injectcenter, Ribeirao Preto, SP, Brazil) at room temperature $\left(23 \pm 2{ }^{\circ} \mathrm{C}\right)$. All participants used all interventions. Each intervention was used for three periods of seven days each in a random sequence. Each sequence of seven days formed a cycle. Thus, each intervention was used for each patient for a total of 21 days (three cycles of 7 days). The experimental period lasted nine weeks.

The biofilm quantification was performed before using the products ("baseline") and after each cycle of seven days. The maxillary internal surfaces were disclosed (1\% neutral red solution) and photographed (Cyber-shot DSC - HX1, Sony, Tokyo, Japan) with standard distance and exposure time. Total surface and the area stained with biofilm were measured $(\mathrm{cm} 2)$ on the photos with the Image Tool 3.00 software (12) (The University of Texas, San Antonio, TE, USA). By these two measurements, the percentage area covered by a biofilm was calculated, which was the outcome of the study. Before the use of the product ("baseline") and after each photograph, the biofilm was eliminated by brushing (Denture brush and Pleasant liquid soap).

For the blinding of the involved parts, the products were distributed in unidentified vials (solutions) and plastic bags (tablets) and delivered without identification. The P1 researcher obtained a list of random numbers (Excel 2013, Microsoft Brazil, Sao Paulo, SP, Brazil), corresponding to the possible sequences of interventions. All possible sentences had the same probability of being assigned. The P2 researcher received random numbers, distributed the products to the participants according to the received codes and provided the hygiene instructions. The P3 researcher was responsible for the collection of the dentures and subsequent total biofilm elimination. The P4 researcher performed the biofilm staining and P5 obtained the photographs of the dentures. The P6 researcher conducted the biofilm quantification, tabulated the variables and forwarded the data to the P1 researcher, who performed the statistical analysis. Thus, all researchers, as well the participants, were blind to the treatment applied.

Sample size was defined according to a comparison between brushing and the associated method (brushing and effervescent tablet) from a previous cross-over trial (6). That trial used similar outcome assessment methods and found differences in a sample of 36 participants. Therefore, this study enrolled a sample of 42 participants, which would allow for a comparable size after accounting for withdrawals and losses.

Statistical analysis was performed using generalized estimating equations (GEE) with a significance level of $0.05 \%$. Due to the wide variation of results and to investigate different responses depending on initial results, baseline data was considered in the analysis. The solutions ("interventions") were inserted as paired samples and the initial data ("baseline") was used as a covariate. Multiple comparisons were performed using the Bonferroni test $(\alpha=0.0167)$. All tests were performed by the SPSS 21.0 software (SPSS Inc., Chicago, IL, USA).

\section{Results}

At the start of the study, of the total of 42 patients, one refused to participate and two were excluded due to the absence of denture biofilm. After the first cycle, of the total of 39 patients, three were excluded, one for the impossibility to stay without the dentures during sleep and two for not using the products (effervescent tablets and sodium hypochlorite). During the other cycles, four participants did not complete the study, one due to travel arrangements and three for not coming to the scheduled appointments (one due to the lack of transportation, two due to illness and four discontinued the intervention). Thus, the final sample included 32 patients, 7 men and 25 women (Fig. 1). Figure 2 shows the biofilm coverage area before and after treatments. No participant experienced any adverse effect such as mucosal pain/soreness or damage to denture base or teeth during this trial.

GEE analysis showed that the biofilm percentage was influenced by the interventions ( $p=0.040$ ). There was an association between baseline values and those obtained after the interventions. However, the interaction between interventions and baseline was not significant $(p=0.319)$. Multiple comparisons found that immersion in 0.5\% sodium hypochlorite $(\mathrm{SH})$ resulted in significantly lower percentage of biofilm $(p<0.001)$ than those found in the control (C) or alkaline peroxide (AP), which did not differ between each other $(p=1.000)$. Confidence intervals for pairwise comparisons range less than $5 \%$ around mean differences (Table 1). 


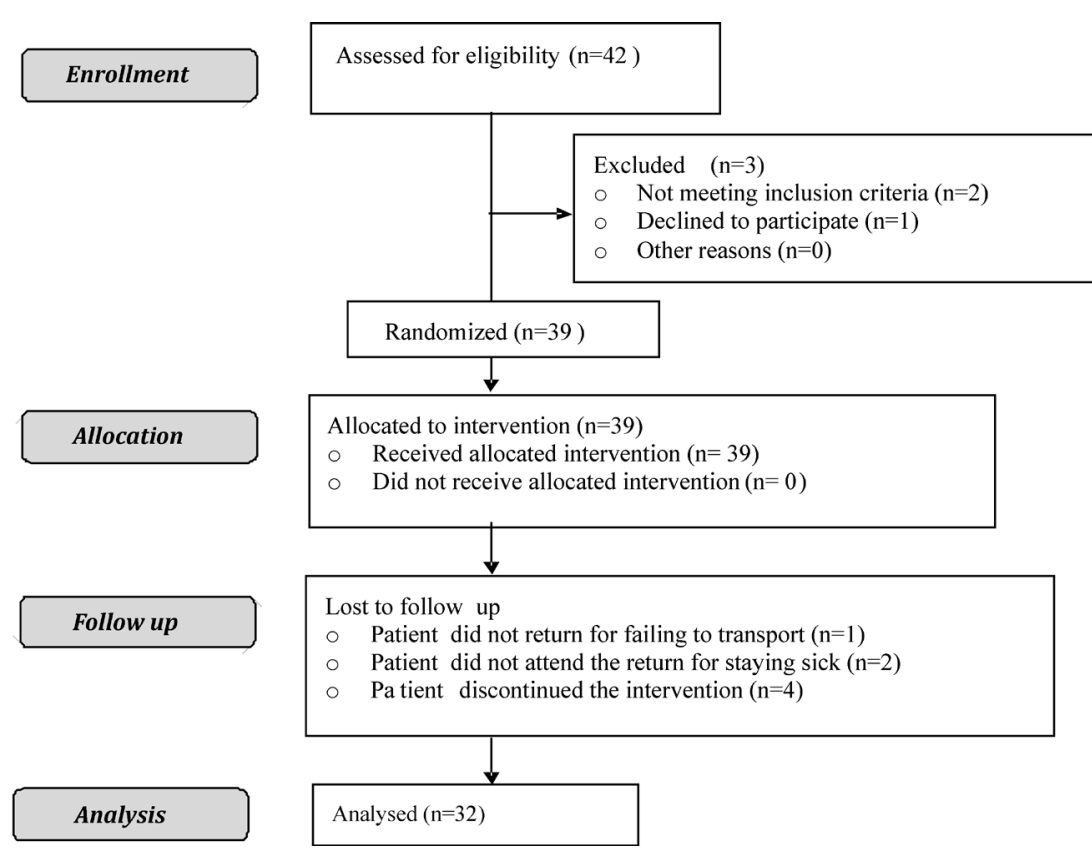

Figure 1. Flowchart of the study participants (Adapted from Consort Statement).

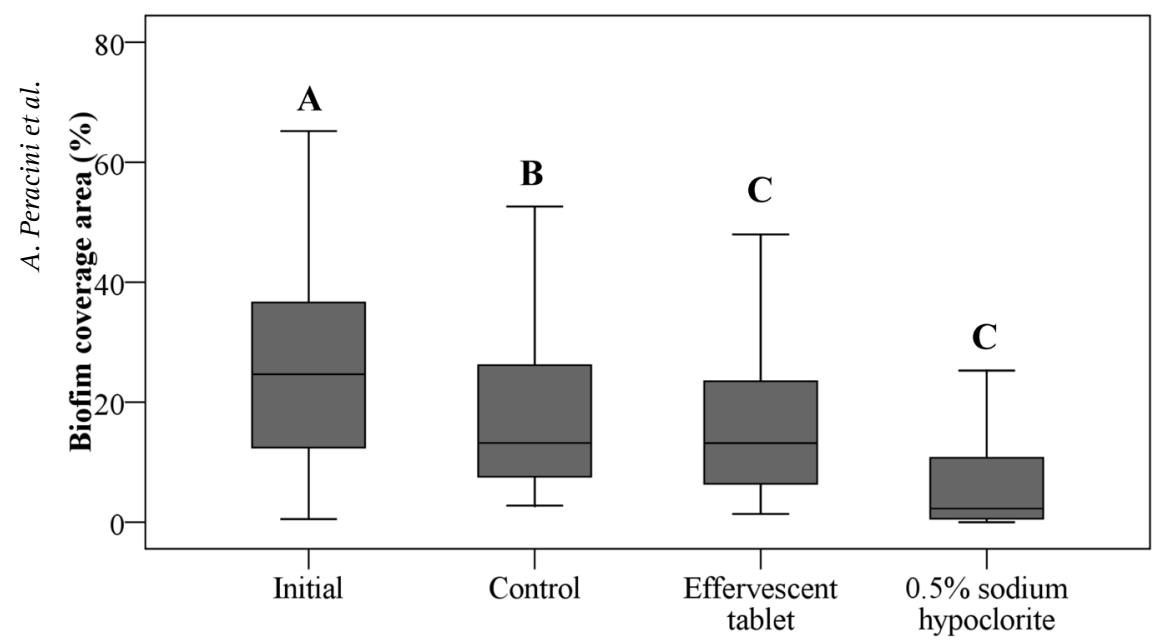

Figure 2. Biofilm coverage area after the use of each product. Different letters indicate statistically significant difference.

Table 1 Estimated mean differences in terms of biofilm coverage area (\%) and respective confidence intervals according to the Bonferroni test

\begin{tabular}{llcccc}
\hline & Comparison & $\begin{array}{c}\text { Difference } \\
\text { between means }\end{array}$ & $\begin{array}{c}\text { Confidence } \\
\text { interval (95\%) }\end{array}$ & $\mathrm{p}$ \\
\hline Control & $\mathrm{X}$ & Effervescent tablet & 0.1 & -3.7 to 3.9 & 1.000 \\
& & & & & \\
Control & $\mathrm{X}$ & $0.5 \%$ sodium Hypochlorite & 9.9 & 6.2 to 13.7 & $<0.001^{*}$ \\
& & & & & \\
Effervescent tablet & $\mathrm{X}$ & $0.5 \%$ sodium hypochlorite & 9.9 & 5.8 a 14.0 & $<0.001^{*}$ \\
\hline
\end{tabular}

*Significant difference $(\mathrm{p}<0.05)$.

702

\section{Discussion}

Thisstudy provided data regarding the efficacy of two major chemical methods for overnight denture cleansing. Results showed that the null hypothesis was rejected because the biofilm coverage was influenced by the interventions, with the sodium hypochlorite as the most efficacious solution. This investigation aimed to minimize risk of bias by using adequate sequence generation and implementation methods (i.e. a concealed, random sequence of interventions) and blinding whenever possible. This latter aspect reinforces conclusions regarding denture biofilm removal for soaking solutions tested.

Previous studies reported the inefficacy of peroxides on biofilm removal when employed as an isolated method $(6,16,23)$. It was also reported that these solutions are effective in few minutes of soaking time $(4,5)$. The different results may be explained by the different methods employed for biofilm quantification, such as computerized or scoring methods, and even by the solutions, once the effectiveness of peroxides may be attributed to the ingredients in the formulations of each cleanser (24). It has been indicated longer periods of immersion aiming an increase in effectiveness $(6,18)$. In disagreement with previous studies $(6,8,10,12)$, our results show that peroxides cannot benefit patients instructed on other good practices for denture maintenance, i.e. regular brushing and overnight removal. Such diverging results may be explained by sample characteristics. Participants were middleaged or independent elderly edentulous patients, with fair systemic status, reasonable compliance and manual dexterity. The moderate 
biofilm coverage on baseline for several participants is suggestive of such profile. Overnight alkaline peroxides might be effective as an adjunctive method for patients with low dexterity, thus compensating the effects of a reduced ability to remove biofilm mechanically (8). Corega Tabs cleanser has shown intermediate activity against yeasts $(7,9,19,24)$ and may improve the effectiveness of hygiene (10). Its efficacious has been attributed to the presence of sodium lauryl sulfate combined with sodium perborate, as well as sodium bicarbonate $(19,24)$.

The efficacy of the hypochlorite is an important result considering the concentration employed, that presents antimicrobial action $(13,19)$ and can minimize adverse effects on materials $(21,22)$. Previous studies have shown the superiority of hypochlorite for removing biofilm when compared to peroxide $(12,23)$, even in overnight immersions $(3,14,15)$; however, the solutions were used at higher concentrations. Present results can be explained by the fact of the alkaline peroxide, as an oxidant product, may affect vital areas of the cell and generate in situ hydroxyl radicals, which exert a more specific action against anaerobes (25). In turn, hypochlorite ions have broader action (23), and therefore greater efficacy, thus explaining differences in removed biofilm. A solution of $0.5 \%$ sodium hypochlorite seems efficacious also when compared to other agents, such as enzyme solution (17) or even Corega tabs for $30 \mathrm{~min}$ (20). Another clinical study found that soaking dentures for 3 $\min$ in $0.5 \% \mathrm{NaOCl}$ for 90 days was an efficacious treatment against Candida spp. and pointed out the antimicrobial activity of $\mathrm{NaOCl}$ on essential enzymatic sites in bacteria, promoting their irreversible inactivation via the action of hydroxyl ions and chloramination (11). The present results are relevant because to best of our knowledge, there is not any ramdomized clinical study in the literature about the effectiveness of $0.5 \% \mathrm{NaOCl}$ as overnight solution.

A limitation of the study was the difficulty in preventing participants to identify the solutions evaluated, because their intrinsic characteristics and odor. Future controlled clinical studies should address the cleansers in different immersion times, focusing on, besides the biofilm removal feature and the antimicrobial action of products against the in vivo biofilm. Previous studies concluded that immersion in these solutions simulating a five-year of $20 \mathrm{~min}$ (22) or 1.5-year of overnight (8h) daily soaking (21) did not cause clinically significant adverse effects on the heat-polymerized acrylic resin. Thus, future studies should address overnight soaking in longer periods of use, simulating a period of denture change and focusing on relevant properties of thermally activated acrylic resin. Finally, this study reinforces that sodium hypochlorite sanitizer can be used as overnight regular denture cleanser, when used at low concentrations. These results can contribute for the indication of this easy and inexpensive chemical solution as auxiliary agent for the mechanical method of brushing.

Overnight immersion in 0.5\% sodium hypochlorite solution was more efficacious for removing biofilm from complete dentures than an effervescent tablet composed by alkaline peroxides. The latter denture cleanser was comparable to an inactive comparator regarding the ability to remove denture biofilm.

\section{Acknowledgements}

The authors thank Viviane Cristina de Oliveira, specialized technician at the School of Dentistry of Ribeirao Preto, University of São Paulo - USP, Brazil, for her assistance in the preparation of specimens. This work was supported by The São Paulo State Research Foundation (FAPESP Grants: 2010/51544-2 and 2010/51543-6).

\section{Resumo}

Este estudo avaliou a eficácia de soluções higienizadoras na remoção do biofilme de dentadura por meio de ensaio clínico randomizado cruzado. Trinta e dois pacientes desdentados foram instruidos a escovar suas dentaduras (escova especifica e sabão líquido) três vezes ao dia (após café da manhã, almoço e jantar) e imergi-las ( $\geq 8$ horas) em: (C) controle água; (PA): peróxido alcalino; ou (HS) hipoclorito de sódio a 0,5\%. Cada solução foi usada por 21 dias (três ciclos alternados de 7 dias). Ao final de cada ciclo, a superficie interna da dentadura maxilar foi evidenciada (vermelho neutro 1\%) e fotografada (HX1- Sony). As áreas (total e corada com biofilme) foram medidas (software Image Tool), e a porcentagem de biofilme calculada como a relação entre a área do biofilme multiplicado por 100 e área da superfície total da base interna da dentadura. Os dados foram comparados por meio de equações de estimação generalizadas $(\alpha=5 \%)$ e comparações múltiplas (Bonferroni - $\alpha=1,67 \%)$. A imersão em HS reduziu o biofilme $(\%)\left(8,3 \pm 13,3^{B}\right)$ em comparação com C $(18,2 \pm$ $\left.14,9^{A}\right)$ e PA $\left(18,2 \pm 16,6^{A}\right)$. A solução de hipoclorito de sódio a $0,5 \%$ foi a mais eficaz na remoção do biofilme. Peróxidos alcalinos podem não levar a maior remoção do biofilme em pacientes com hábitos adequados de manutenção de dentadura.

\section{References}

1. Felton D, Cooper L, Duqum I, Minsley G, Guckes A, Haug S et al. Evidence-based guidelines for the care and maintenance of complete dentures: a publication of the American College of Prosthodontics. J Prosthodont 2011;20:1S1-12.

2. Souza RF, de Freitas Oliveira Paranhos $\mathrm{H}$, Lovato da Silva $\mathrm{CH}, \mathrm{Abu}-$ Naba'a L, Fedorowicz Z, Gurgan CA. Interventions for cleaning dentures in adults. Cochrane Database Syst Rev 2009;4:CD007395.

3. Kulak Y, Arikan A, Albak S, Okar I, Kazazoğlu E.Scanning electron microscopic examination of different cleaners: surface contaminant removal from dentures. J Oral Rehabil 1997;24:209-215.

4. Sheen SR, Harrison A. Assessment of plaque prevention on dentures using an experimental cleanser. J Prosthet Dent 2000;84:594-601.

5. Gornitsky M, Paradisl I, Landaverde G, Malo AM, Velly AM. A clinical and microbiological evaluation of denture cleansers for geriatric patients in long-term care institutions. J Can Dent Assoc 2002;68:39-45.

6. Paranhos HFO, Silva-Lovato $\mathrm{CH}$, Souza RF, Cruz PC, Freitas KM, Peracini A. Effects of mechanical and chemical methods on denture biofilm accumulation. J Oral Rehabil 2007;34:606-612.

7. Andrade IM, Cruz PC, Silva CH, Souza RF, Paranhos HFO, Candido RC, Marin JM, Souza-Gugelmin MC. Effervescent tablets and ultrasonic devices against Candida and mutans streptococci in denture biofilm. 
Gerodontology 2010; 28:264-270.

8. Silva-Lovato $\mathrm{CH}$, De Wever $\mathrm{B}$, Adriaens $\mathrm{E}$, Watanabe $\mathrm{E}$, Paranhos HFO, Souza RF, et al.. Clinical and antimicrobial efficacy of NitrAdine -based disinfecting cleaning tablets in complete denture wearers. J Appl Oral Sci 2010;18:560-565.

9. Fernandes FSF, Pereira-Cenci T, Silva WJ, Ricomini AP, Straioto FF, Del Bel Cury AA. Efficacy of denture cleansers on Candida spp. biofilm formed on polyamide and polymethil methacrylate resins. J Prosthet Dent 2010;105:51-58.

10. Cruz PC, Andrade IM, Peracini A, Souza-Gugelmin MC, Silva-Lovato CH, Souza RF et al.. The effectiveness of chemical denture cleansers and ultrasonic device in biofilm removal from complete dentures. J Appl Oral Sci 2011;19:668-673.

11. Sousa Porta SR, Lucena-Ferreira SC, Silva WJ, Del Bel Cury AA. Evaluation of sodium hypochlorite as a denture cleanser: a clinical study. Gerodontology 2015;32:260-266.

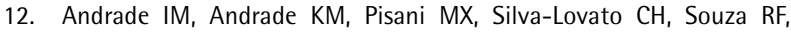
Paranhos HFO. Trial of an experimental castor oil solution for cleaning dentures. Braz Dent J 2014;25:43-47.

13. Salles MM, Badaró MM, Arruda CNF, Leite VMF, Silva-Lovato $\mathrm{CH}_{\text {, }}$

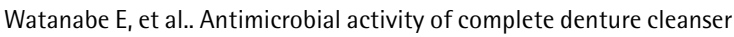
solutions based on sodium hypochlorite and Ricinus communis - a randomized clinical study. J Appl Oral Sci 2015;23:637-642.

14. Hutchins DW, Parker WA. A clinical evaluation of the ability of denture cleaning solutions to remove dental plaque from prosthetic devices. $\mathrm{N}$ Y State Dent J 1973;39:363-367.

15. Rustogi KN, Mellberg JR, Schlissel HJ, Hansen KR, Volpe AR. The clinical efficacy of denture cleansers. Q Natl Dent Assoc 1979;37:100-106.

16. Keng SB, Lim M. Denture plaque distribution and the effectiveness of a perborate-containing denture cleanser. Quintessence Int 1996;27:341345 .
17. Lima EM, Moura JS, Del Bel Cury AA, Garcia RC, Cury JA. Effect of enzymatic and $\mathrm{NaOCl}$ treatments on acrylic roughness and on biofilm accumulation. J Oral Rehabil 2006;33:356-362.

18. Augsburger RH, Elahi JM. Evaluation of seven proprietary denture cleansers. J Prosthet Dent 1982;47:356-359.

19. Vieira APC, Senna PM, da Silva WJ, Del Bel Cury AA. Long-term efficacy of denture cleansers in preventing Candida spp. biofilm recolonization on liner surface. Braz Oral Res 2010;24:342-348.

20. Rossato MB, Unfer B, May LG, Braun KO. Analysis of the effectiveness of different hygiene procedures used in dental prostheses. Oral Health Prev Dent 2011;9:221-227.

21. Paranhos HFO, Peracini A, Pisani MX, Oliveira VC, Souza RF, Silva-Lovato $\mathrm{CH}$. Color stability, surface roughness and flexural strength of an acrylic resin submitted to simulated overnight immersion in denture cleansers. Braz Dent J 2013;24:152-156.

22. Arruda CNF, Sorgini DB, Oliveira VC, Macedo AP, Silva-Lovato $\mathrm{CH}_{\text {, }}$ Paranhos HFO. Effects of denture cleansers on heat-polymerized acrylic resin: A five-year-simulated period of use. Braz Dent J 2015;26:404408.

23. Kempler D, Myer M, Kahl EA, Martin DW. The efficacy of sodium hypochlorite as a denture cleanser. Spec Care Dentist 1982;2:112-115.

24. Coimbra FCT, Salles MM, Oliveira VC, Macedo AP, Silva CHL, Pagnano $\mathrm{VO}$ et al. Antimicrobial action of complete denture cleansers (alkaline peroxides) against specific microorganisms. Am J Dent 2016;29:149-53.

25. Paranhos HFO, Silva-Lovato $\mathrm{CH}$, Souza RF, Cruz PC, de Freitas-Pontes KM, Watanabe E et al.. Effect of three methods for cleaning dentures biofilms formed in vitro on acrylic resin. J Prosthodont 2009;18:427431.

Received March 18, 2016 Accepted September 1, 2016 